\title{
Preferences for figural complexity as a function of cognitive style
}

\author{
ALAN G. FROST and MARTIN S. LINDAUER \\ State University of New York, Brockport, New York 14420
}

\begin{abstract}
Twelve pairs of nonsense visual stimuli of different degrees of complexity were presented to 42 undergraduate subjects equally divided by sex into field independents and field dependents. Dependents preferred the simple stimuli more than independents did, and the reverse was true for complex stimuli. These findings conformed to expectations about the different ways in which field independents and dependents process information. In general terms, field independents are challenged, whereas dependents are overwhelmed by complex stimuli; on the other hand, independents are bored by simple stimuli, whereas dependents are able to go beyond their literal properties. The results were discussed in terms of the link between cognitive science and cognitive style, that is, as an emphasis on both stimulus processing and perceiver differences in processing, respectively.
\end{abstract}

It is an accepted assumption that the ability to organize environmental input depends not only on the person's cognitive skills, but also on the nature of the stimulus; that is, personality and perception are related (Witkin, Lewis, Hertzman, Machover, Meissner, \& Wapner, 1954). This means, for example, that preferences for different degrees of figural complexity will vary as a function of differences in perceivers' capacity to structure such input (Munsinger \& Kessen, 1964).

Yet studies of the cognitive structure of the stimulus, for example, its complexity (Berlyne, 1960; Dember \& Earl, 1957; Dember \& Warm, 1979), pay more attention to the stimulus than to the role of individual differences, for example, the field-independence and field-dependence mode of cognitive style. On the other hand, studies of the cognitive style of the perceiver, at least those that represent the large number that concentrate on field independence and dependence, also take a restricted approach to the phenomenon. The cognitive structure of the stimulus is held constant, and cognitive differences between perceivers are emphasized (Goodenough, 1976; Long, 1974).

Consider the classic monograph by Munsinger and Kessen (1964), one of the first to stress the importance of the affective, motivational, and cognitive demands of stimulus variation. They found that preferences for irregularly shaped polygons that differed in complexity (i.e., the number of turns) conformed to a U-shaped function. For example, stimuli of intermediate degrees of complexity (8-16) turns were preferred over the very simple (5-6 turns) and the very complex (20-40 turns) (Munsinger \& Kessen, 1964, p. 11). But of the nine studies reported, all but one concentrated on stimulus attributes (e.g., familiarity, meaningfulness). The exception (Study 6) showed that artists, whose background in managing extremely complex forms is unique, shifted their preferences toward the very complex stimuli (i.e., a linear trend was found). (See also Munsinger
\& Kessen, 1964, Footnotes 3 and 5 , in which it is suggested that other sources of individual differences, in level of education, sophistication, and training, could also lead to increases in preferences for complex forms.)

The following line of reasoning, summing up our perceptual-cognitive knowledge about field independence/dependence (Witkin, Ottman, Raskin, \& Karp, 1971), leads to several testable hypotheses about preferences for forms of different complexity. Field independents are less dominated by the visual field than are field dependents: The former are better able to disembed hidden figures from a complex matrix of forms and can ignore the influence of a tilted frame in setting a rod to the vertical. Field independents are more analytical and differentiated in their perceptions, whereas field dependents are more global and intuitive. In the language of information processing, field independents (compared with field dependents) have a less limited channeling capacity and a better set of coding rules with which to process incoming signals. Consequently, field independents are less likely to be overwhelmed, overloaded, or confused by extremely complex stimuli. Complex stimuli, compared with simple stimuli, are more challenging and less boring to the field independent. Thus, it is hypothesized that field independents will prefer complex forms over simple forms. On the other hand, field dependents are less capable of handling large amounts of stimulus uncertainty than are field independents. Hence, field dependents should prefer the simple over the complex. Simple stimuli more easily lend themselves to mental manipulations (i.e., being played and toyed with for exploratory purposes). In short, preferences for simple and complex forms should vary as a function of field independence/dependence.

\section{METHOD}

Fifty-eight volunteer undergraduates from several general psychology classes were given a modified version of the group 
Hidden Figures Test (HFT) (Educational Testing Service, 1962; Jackson, Messick, \& Myers, 1964). The subjects had $10 \mathrm{~min}$ in which to find 16 simple figures embedded in 16 complex patterns. The figures were arranged in a booklet, with each page containing both the simple and the complex stimulus; the latter was located below the former. (These modifications made the task less one of memory and more one of perception.) Two groups of 21 subjects each were drawn from the larger group of 58 subjects (men $=9$, women $=12$ in each group). The 42 subjects fell at either the low end (field-dependent subjects) or the high end (field-independent subjects) of the HFT distribution of scores (1-10 and 12-16, respectively; the scores reflect the number of hidden figures successfully traced). Most of the 16 excluded subjects fell within the middle range of scores, with a few subjects at the extremes randomly excluded in order to assign an equal number of men and women to each group. (An additional six subjects had served earlier in a pretest.) The mean HFT scores (and standard deviations) for the fielddependent men and women were 5.22 (3.63) and 5.00 (2.49), respectively; for the field-independent group, the HFT scores for men and women were $15.22(.83)$ and $13.50(1.24)$, respectively. The overall HFT means for the 29 men and 29 women were $11.07(4.65)$ and $9.45(4.33)$, respectively. Following the HFT, all subjects were given the preferential task described next.

Three sets of 12 random polygons, containing 3-40 turns, were taken from Munsinger and Kessen $(1964$, p. 7). Pairs of stimuli, randomly taken from one of the three sets, were presented in one of three random orders; the left- and right-hand members of the pair were also alternated whenever the pairs were presented again. Members of the pair were simultaneously presented adjacent to each other in a dimly lit room for $5 \mathrm{sec}$ (with the next set of stimuli following immediately) to small groups of subjects $($ mode $=3$, range $=1-5)$. The screen size filled by the pair was $185 \times 185 \mathrm{~cm}$. Subjects were seated $1.15-3.50 \mathrm{~m}$ away from the screen, at about a 10- to 20-deg angle from the screen.

Subjects indicated on a sheet before them the member of the pair they preferred by circling an " $L$ " (for left-hand member of the pair) or an " $R$ " indicator. They were encouraged to make a choice in every instance. A total of 66 comparisons were made by each subject; that is, each of the 12 stimuli was compared with all 11 others. The procedure outlined above follows that of Munsinger and Kessen (1964). However, the analysis was based on the method of paired comparisons described in Woodworth and Schlosberg (1954, pp. 252-256). Preference scores in this analysis are defined as the number of other stimuli preferred. For example, a preference score of 7 for a three-turn stimulus means that this stimulus was preferred over seven other stimuli. A score of 4 means that this stimulus was less preferred; that is, it was preferred over four other stimuli. Thus, the higher the score, the greater the preference for a given stimulus. (A maximum score is 11.) The study lasted about $45 \mathrm{~min}$ (and included a 5 -min debriefing to explain the nature of the study).

\section{RESULTS}

The shape of the two curves for the field independents and field dependents did differ as predicted (see Figure 1). Field dependents, compared with field independents, preferred simple stimuli (i.e., stimuli at 3,5 , and 6 turns), and field independents, compared with field dependents, preferred complex stimuli (i.e., stimuli at 25,31 , and 40 turns). The two groups were not distinguishable in the middle ranges of complexity (8-16 stimulus turns). Not shown, although worth noting, is the appearance of the graph for the combined groups. It conformed to the usual inverted-U shape, except at the extremes, which is where the field independents and

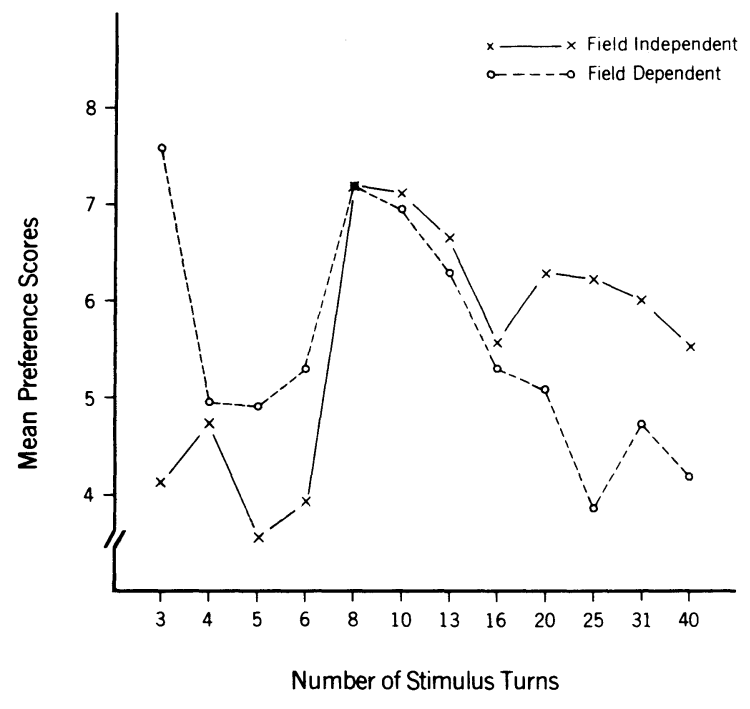

Figure 1.

field dependents most markedly diverged from one another. Munsinger and Kessen (1964, p. 11) found a similar irregular pattern at the extremes, suggesting that individual differences may have also played a role in their results.

Munsinger and Kessen (1964, pp. 6-8) held that it is the shape of the curve, rather than an analysis of statistical differences, which is the primary type of data for this type of study. Nevertheless, statistical comparisons between field independents and field dependents can be made, but somewhat inelegantly. Preferences by each group at each of the 12 stimuli can be considered separately. (With each subject responding to every stimulus, there is no between-subjects variability. Hence, the most efficient statistic, a repeated analysis of variance, cannot be performed.) The Fs for the simple stimuli (the first four) were $21.86, .10,5.55$, and 3.09 , respectively; the Fs for the complex stimuli (the last four) were $3.21,9.80,2.48$, and 2.03 , respectively; and the Fs for stimuli of intermediate complexity (the middle four) were all less than $1(.03, .23, .77$, and .05 , respectively). A liberal interpretation of these statistics, including the three significant $\mathrm{Fs}[\mathrm{Fs}(1,38) \geqslant 4.10$, ps $<.05]$ and the three $F s$ in the expected direction $[\mathrm{Fs}(1,38) \geqslant 2.00$, ps $<.20]$, indicates that as many as three and four comparisons in the set of simple and complex figures, respectively, conformed to the hypothesis.

This differential pattern is more clearly seen by combining the data for the 12 stimuli into three sets, simple, intermediate, and complex (Figure 2). Comparisons between the field independents and the field dependents at each of these three levels of complexity reveal a statistically significant difference at the simple and complex ends of the continuum, but none at the intermediate level $[\operatorname{ts}(19)=2.94,2.72$, and .52 , respectively, ps $<.01$, one-tailed test).

Sex differences played little or no role in the results. 


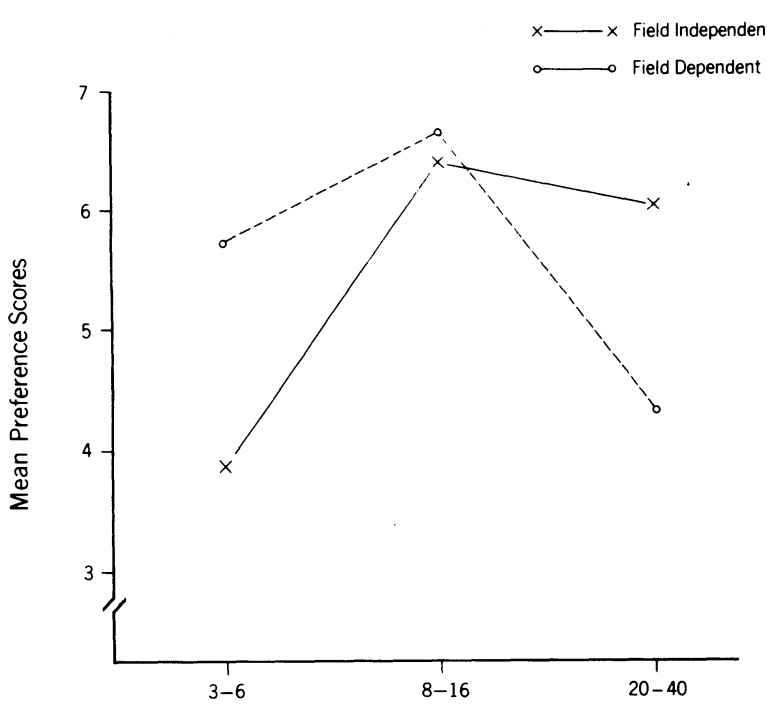

Number of Stimulus Turns

Figure 2.

They did not distinguish between the preference scores for the 12 stimuli $[\mathrm{F}<1$ in 10 of the $12 \mathrm{com}$ parisons; $\operatorname{Fs}(1,38) \leqslant 2.67$, ps $>.05$, in the remaining two cases). Nor did sex differences interact with the field-independent/dependent distinction, with one exception. Sex was a factor for the 10-turn stimulus $[F(1,38)$ $=9.98, p<.01]$, on which field-independent men scored higher than both groups of women and the fielddependent males. Except for this single isolated instance, the interaction between sex and cognitive style in all other cases was not significant $[\mathrm{F}(1,38) \leqslant 1.91, \mathrm{p}>.05]$.

\section{DISCUSSION}

Field independents, as hypothesized, preferred the complex stimuli more than dependents did. The ability of independents to disembed complex stimuli prevented them from becoming confused (as, presumably, the field dependents were). The analytical skills of the field independents were challenged, whereas the holistic intuitions of the field dependents were overwhelmed. Field dependents, on the other hand, preferred the simple stimuli more than the field independents did (as hypothesized). Perhaps they were able to enrich what field independents would consider to be impoverished and rather dull kinds of input. Personality differences therefore mattered at the extremes of input. But at intermediate degrees of complexity, which probably account for the majority of input, preferences were equal (and high) in both groups of subjects.

These results reaffirm the general relationship between personality and perception and establish a link between cognitive style and figural preference. Thus, current developments in cognitive science are linked to an older concern with cognitive style. Most information processing models usually overlook these relationships; their impersonality leads them to neglect the "person" in favor of the "process" (Dember \& Warm, 1979, Chapter 12). These results, however, indicate that the arousal properties of stimuli also depend on the perceiver's characteristic source of arousal, that is, on whether the perceiver is tuned to internal or external events. Vaught and Roodin (1973), in a different but related context, have also shown that form dis- crimination depends on the field-independence/dependence distinction.

It would be interesting to know whether preferential differences to nonsense stimuli also hold for environmental events. For example, do field dependents prefer the pastoral countryside, whereas field independents prefer the bustling city life? This question has in fact been indirectly addressed by the SensationSeeking Scale (Zuckerman \& Link, 1968). This is a self-report inventory of preferences for different environmental sources of stimulation. Unfortunately, the findings for field independents and dependents on this measure have not been consistent (Farley, 1974). It may be that degree of stimulation and complexity are not synonymous.

In addition, a paper-and-pencil test of preferences is not a sufficiently realistic representation of environmental demands. An alternative is to place field independents and dependents in an actual environmental setting (Samuelson \& Lindauer, 1976). For example, field independents would be under less stress and feel more comfortable in a messy room than would field dependents. Thus, their responses to various tasks (e.g., time estimation, anagram solution, and art judgment), compared with field dependents, should be unaffected, if not positively influenced. Field dependents, on the other hand, should respond poorly in the messy room and more favorably in the neat room.

The forging of a tie between cognitive style and environmental psychology suggested above is long overdue. The fieldindependent/dependent distinction is a robust construct in many fields of psychology. It should play a similar role in the emerging topics of environmental perception, personal space, crowding, and privacy.

Returning to the laboratory approach to figural preference, there remain several unanswered questions. The equivalence between the complexity of a stimulus and the number of turns it contains has been assumed rather than tested. Thus, judgments of subjective complexity have to be obtained for stimuli of different physical complexity. Directly relevant to the present findings is the question of how to account for the preferential distinctions between field independents and field dependents. The beginnings of an answer may lie in a study of the meaningfulness of the stimuli. These could be obtained either through ratings of meaningfulness or by the number of associations the stimuli evoke. Thus, an appropriate next step would be to examine differences between field dependents and field independents in their judgments of the meaningfulness of simple and complex stimuli.

\section{REFERENCES}

Berlyne, D. E. Conflict, arousal, and curiosity. New York: McGraw-Hill, 1960.

Dember, W. N., \& EARL, R. W. Analysis of exploratory, manipulatory and curiosity behaviors. Psychological Review, 1957, 64, 91-96.

Dember, W. N., \& Warm, J. S. Psychology of perception (2nd ed.). New York: Holt, Rinehart, \& Winston, 1979.

Educational Testing Service. Hidden Figure Test $V$. Atlanta, Ga: Author, 1962.

FARLEY, F. H. Sensation-seeking motive and field independence. Perceptual and Motor Skills, 1974, 38, 330.

Goodenough, D. R. The role of individual differences in field dependence as a factor in learning and memory. Psychological Bulletin, 1976, 83, 675-694.

Jackson, D. N., Messick, S., \& Myers, C. T. Evaluations of group and individual forms of embedded-figures measures of field-independence. Educational and Psychological Measurement, 1964, 24, 177-192.

LONG, G. M. Reported correlates of field dependency-independency dimension. JSAS Catalog of Selected Documents in Psychology, 1974, 4, 1-29. (Ms. No. 540) 
Munsinger, H., \& Kessen, W. Uncertainty, structure, and preference. Psychological Monographs, 1964, 78(Whole No. 586).

Samuelson, D., \& Lindauer, M. S. Perception, evaluation, and performance in a neat and messy room by high and low experience seekers. Environment and Behavior, 1976, 8, 291-306.

Vaught, G. M., \& Roodin, P. A. Cognitive style, performance and form discrimination. Social Behavior and Personality, 1973, 1, 17-22.

Witkin, H. A., Lewis, H. B., Hertzman, M., Machover, K., Meissner, P., \& W APner, S. Personality through perception. New York: Harper, 1954.
Witkin, H. A., Ottman, P. K., Raskin, E., \& KarP, S. A. Manual for the Embedded Figures Tests. Palo Alto, Calif: Consulting Psychologists Press, 1971.

Woodworth, R. S., \& Schlosberg, H. Experimental psychology (Rev. Ed.). New York: Holt, 1954.

Zuckerman, M., \& Link, K. Construct validity for the sensationseeking scale. Journal of Consulting and Clinical Psychology, $1968,32,420-426$.

(Received for publication June 30, 1980.) 